\title{
Abnormal expression of matrix metalloproteinase-9 (MMP9) correlates with clinical course in Chinese patients with endometrial cancer
}

\author{
Fang Yu ${ }^{\mathrm{a}, \mathrm{c}, 1}$, Qingping Jiang ${ }^{\mathrm{c}, 1}$, Ying Zhou ${ }^{\mathrm{b}, 1}$, Zhen Yang ${ }^{\mathrm{b}}$, Xiaoli Yu ${ }^{\mathrm{b}}$, Hao Wang ${ }^{\mathrm{b}}$, Zhen Liu ${ }^{\mathrm{d}}$, \\ Lijing Wang ${ }^{\mathrm{a}}$, Weiyi Fang ${ }^{\mathrm{b}, *}$ and Suiqun Guo ${ }^{\mathrm{a}, *}$ \\ ${ }^{a}$ Department of Obstetrics and Gynecology, The Third Affiliated Hospital of Southern Medical University, \\ Guangzhou, China \\ ${ }^{\mathrm{b}}$ Cancer Research Institute, Southern Medical University, Guangzhou, China \\ ${ }^{\mathrm{c}}$ Department of Pathology, Third Affiliated Hospital of Guangzhou Medical College, Guangzhou, China \\ ${ }^{\mathrm{d}}$ Department of Pathology, Basic School, Guangzhou Medical College, Guangzhou, China
}

\begin{abstract}
Aims and background: The aim of the present study was to analyze the expression of matrix metalloproteinase- 9 (MMP9) in endometrial cancer and its correlation with clinicopathologic features in Chinese patients, including the survival of patients with endometrial cancer.

Methods: Using immunohistochemistry analysis, we analyzed MMP9 protein expression in clinicopathologically characterized 128 endometrial cancer $(\mathrm{EC})$ cases with age ranging from 30 to 85 years (median $=51.6$ years) and 30 endometrial atypical hyperplasia (EAH) and 30 normal endometrium (NE). Cases with greater than or equal to 6 and less than 6 with the score value of cytoplasmic MMP9 immunostaining were regarded as high expression and low expression, respectively. The relationship between the expression levels of MMP9 and clinical features was analyzed in EC cases.

Results: Immunohistochemical analysis revealed that the protein expression of MMP9 detected in EC tissues was higher than that in the EAH tissues and NE tissues $(P=0.006)$. In addition, high levels of MMP9 protein were positively correlated with the status of lymph node metastasis $(P=0.044)$ and the histopathological grade $(P<0.05)$ of EC patients. Patients with higher MMP9 expression did not correlate with EC patients' clinical outcome in China. Multivariate analysis suggested that status of lymph node metastasis and depth of myometrial invasion, but not MMP9 expression level, were significantly correlated with patients' survival.

Conclusion: MMP9 is highly expressed in ECs and correlates with the progression of ECs, but not be helpful in predicting the prognosis of EC patients.
\end{abstract}

Keywords: Matrix metalloproteinase-9, endometrial cancer, Chinese patients

\section{Introduction}

Endometrial carcinoma represents the most frequently diagnosed malignancy of the female genital tract worldwide, but incidence varies among different coun-

\footnotetext{
${ }^{1}$ These authors contributed equally to this work.

*Corresponding author. E-mail: fangweiyi1975@yahoo.com.cn, guosq2005@126.com.
}

tries [1]. The disease often causes abnormal bleeding as a first symptom and is therefore usually detected in its early stages (FIGO stage I). When diagnosed at early stages of the disease, this type of cancer is a highly curable malignancy with a 5-year relative survival rate of more than $80 \%$ [2]. However, there are a group of patients with a high risk of cancer recurrence or metastatic spread.

MMP9, a member of the matrix metalloproteinases 
(MMPs), plays a critical role in breakdown of extracellular matrix in normal physiological processes, such as embryonic development, reproduction, and tissue remodeling, as well as in disease processes, such as tumor metastasis [3]. MMP9 is secreted from cells and, once activated, is thought to degrade collagen in the extracellular matrix, which promotes the metastasis of tumor cells [4].

So far, there have been a few studies concerning MMPS in endometrial cancer [5-10]. In the previous studies, researchers had demonstrated that MMP9 was over-produced in human endometrial carcinomas as compared with control non-carcinoma endometrial tissues. However, some issuses were still controversial about MMP9 expression correlated to clinicopathologic features in endometrial cancer, including the prognostic value of MMP9. Therefore, the aim of this work was to study the connections between gelatinase expression and the clinicopathologic features in Chinese patients with EC, including the survival of patients. We found that the protein expression levels of MMP9 were higher in EC tissues than those in non-cancerous endometrial tissues (EAHs and NEs). Furthermore, the level of MMP9 protein expression was correlated with the progression, but no association with overall survival of EC patients.

\section{Materials and methods}

\subsection{Sample collection}

From 2002 to 2007, formalin-fixed and paraffin embedded samples of 30 normal endometria, 30 samples of endometrial atypical hyperplasia and 128 samples of endometrioid carcinoma were obtained in the Third Affiliated Hospital of Guangzhou Medical School, Guangzhou City, China. None of the 128 patients with endometrioid carcinoma received chemotherapy or radiotherapy before surgery, which consisted of peritoneal cytology, total hysterectomy, bilateral salpingooophorectomy, and pelvic and para-aortic lymph node sampling when necessary. In the $128 \mathrm{EC}$ cases, the median age of the patients was 51.6 years (range from 30 to 85$)$. The clinical follow-up time of patients ranged from 48 to 108 months. For the use of these clinical materials for research purposes, prior consents from the patients and approval from the Ethics Committees of this hospital were obtained. All specimens had confirmed pathological diagnosis and were staged according to the FIGO 2009.

\subsection{Immunohistochemistry}

Paraffin sections $(3 \mu \mathrm{m})$ from samples of $128 \mathrm{EC}$ and $30 \mathrm{EAH}$ and $30 \mathrm{NE}$ specimens were deparaffinized in $100 \%$ xylene and re-hydrated in descending ethanol series $(100 \%, 90 \%, 80 \%, 70 \%$ ethanol) and water according to standard protocols. Heat-induced antigen retrieval was performed in $10 \mathrm{mM}$ citrate buffer for $2 \mathrm{~min}$ at $100^{\circ} \mathrm{C}$. Endogenous peroxidase activity and nonspecific antigen were blocked with peroxidase blocking reagent containing $3 \%$ hydrogen peroxide and serum, followed by incubation with goat anti-human MMP9 antibody (1:100) (Sc6840, Santa, MA, USA) for $1 \mathrm{~h}$ at $37^{\circ} \mathrm{C}$. After washing, the sections were incubated with biotin-labeled rabbit anti-goat antibody for $10 \mathrm{~min}$ at room temperature, and subsequently were incubated with streptavidin-conjugated horseradish peroxidase (HRP) (Maixin Inc, China). The peroxidase reaction was developed using 3, 3 diaminobenzidine chromogen solution in DAB buffer substrate. Sections were visualized with DAB and counterstained with hematoxylin, mounted in neutral gum, and analyzed using a bright field microscope.

\subsection{Evaluation of staining}

The immunohistochemically stained tissue sections were reviewed and scored separately by two pathologists blinded to the clinical parameters. The staining intensity was scored as previously described [11,12]. The extent of the staining, defined as the percentage of positive staining areas of tumor cells or normal nasopharyngeal epithelial cells in relation to the whole tissue area, was scored on a scale of 0 to 4 as the following: $0,<10 \% ; 1,10-25 \% ; 2,26-50 \% ; 3,50-$ $75 \%$; and $4,>76 \%$. The sum of the staining intensity and staining-extent scores was used as the final staining score for MMP9 (0-7). For statistical analysis, a final staining scores of $0-5$ and 6-7 were respectively considered to be low and high expression.

\subsection{Statistical analyses}

All statistical analyses were performed using SPSS 13.0 software. The $\chi 2$ test was used to analyze the relationship between the levels of MMP9 expression and clinicopathologic characteristics. Survival curves were plotted using the Kaplan-Meier method and compared using the log-rank test. The significances of various variables in survival were analyzed using multivariate cox proportional hazards model. A $P$ value of less than 0.05 was considered statistically significant. 


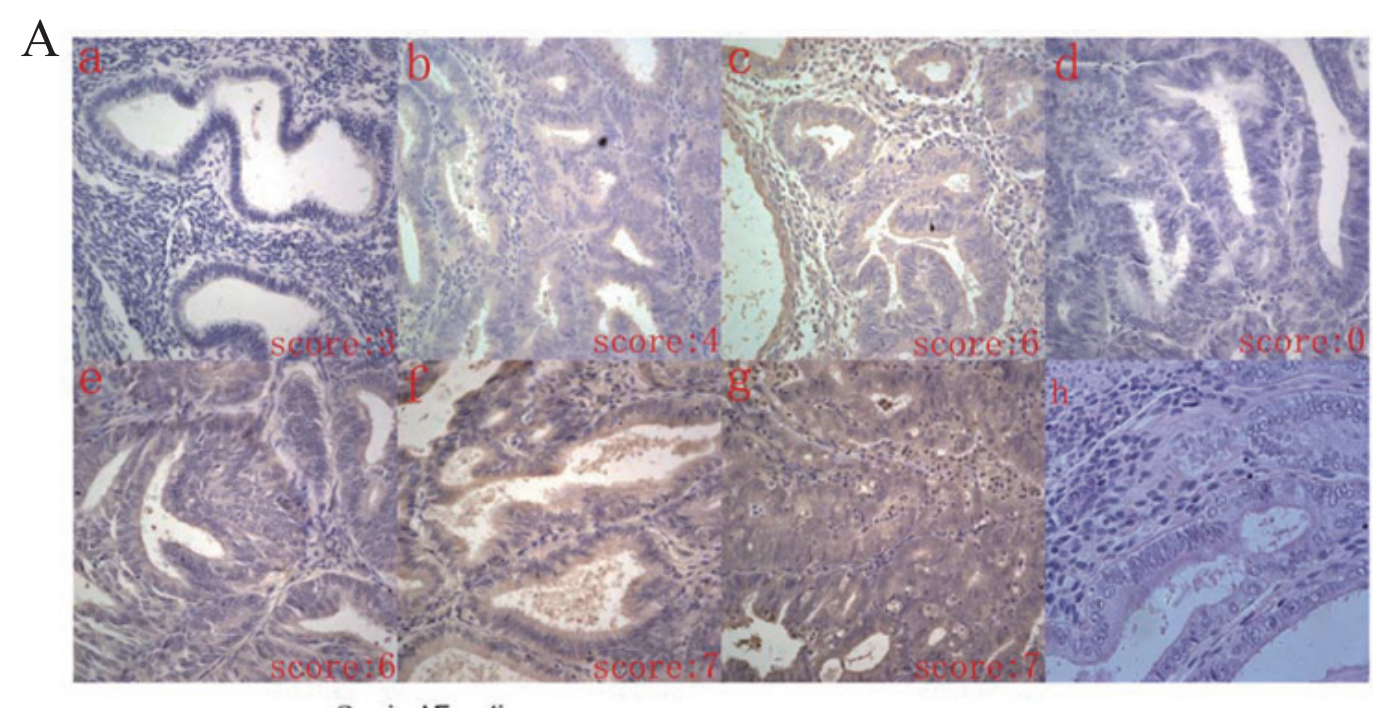

$\mathrm{B}$

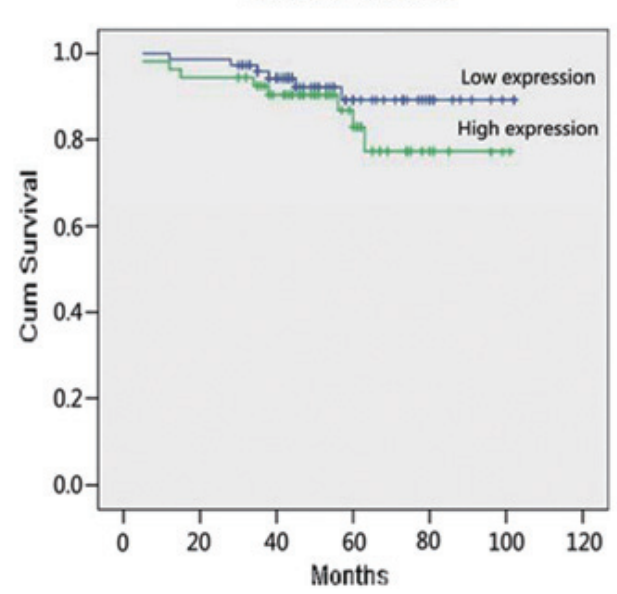

Fig. 1. Kaplan-Meier plots of overall survival duration in patients with EC. MMP9 protein expression in EC and EAH and NE samples(A): a: Weak expression of MMP9 in NE sample; b: Weak expression of MMP9 in EAH sample; c: Strong staining of MMP9 in EAH samples; d: Negative expression of MMP9 in EC samples(original magnification 400×); e-g:Strong staining of MMP9 in EC samples (original magnification $400 \times$ ). h: H\&E staining in EC samples. Kaplan-Meier survival analysis of overall survival duration in 128 EC patients according to MMP9 protein expression (B): The log-rank test was used to calculate $p$ values.

\section{Results}

\subsection{Immunohistochemical analysis of MMP9 protein} expression in endometrial cancer, endometrial atypical hyperplasia $(E A H)$ and normal endometrium (NE) tissues

We measured the expression levels and subcellular localization of MMP9 protein in 128 archived paraffinembedded EC samples, $30 \mathrm{EAH}$ samples and $30 \mathrm{NE}$ samples using immunohistochemical staining (Fig. 1A-G). Specific MMP9 protein staining was found in the cytoplasm of non-cancerous and malig- nant epithelial cells. Furthermore, we observed that in $42.2 \%(54 / 128)$ of EC samples, MMP9 protein was highly expressed. In comparison, highly expressed MMP9 protein of EAH and NE samples was $26.7 \%$ and $16.7 \%$, respectively, which was significantly lower than that in the EC samples $(P=0.006)$ (Table 1$)$.

\subsection{Relationship between clinicopathological characteristics and MMP9 expression endometrial cancer in patients}

The relationships between clinicopathological characteristics and MMP9 expression levels in individuals 
Table 1

Protein expression of MMP9 in normal endometrium (NE), endometrial atypical hyperplasia (EAH) and endometrial cancer (EC) samples

\begin{tabular}{lcccc}
\hline \multicolumn{5}{c}{ Protein expression } \\
\hline Group & Cases & Low expression & High expression & P value \\
\hline NE & 30 & $25(83.3)$ & $5(16.7)$ & \\
EAH & 30 & $22(73.3)$ & $8(26.7)$ & \\
EC & 128 & $74(57.8)$ & $54(42.2)$ & 0.006 \\
\hline
\end{tabular}

Table 2

Clinicopathologic characteristics of patient samples and expression of MMP9 in EC

\begin{tabular}{|c|c|}
\hline & $\mathrm{N}(\%)$ \\
\hline \multicolumn{2}{|l|}{ Age $(y)$} \\
\hline$<50$ & $42(32.8)$ \\
\hline$\geqq 50$ & $86(67.2)$ \\
\hline \multicolumn{2}{|l|}{ Menopausal status } \\
\hline Premenopausal & $69(53.9)$ \\
\hline Postmenopausal & $59(46.1)$ \\
\hline \multicolumn{2}{|l|}{ FIGO stage } \\
\hline I-II & $108(84.4)$ \\
\hline III & $20(15.6)$ \\
\hline \multicolumn{2}{|l|}{ Histological grading } \\
\hline G1 & $56(43.8)$ \\
\hline $\mathrm{G} 2$ & $57(44.5)$ \\
\hline G3 & $15(11.7)$ \\
\hline \multicolumn{2}{|l|}{ Depth of myometrial invasion } \\
\hline$<50 \%$ & $91(71.1)$ \\
\hline$\geqq 50 \%$ & $37(28.9)$ \\
\hline \multicolumn{2}{|l|}{ Histologic subtype } \\
\hline Endometrioid adenocarcinoma & $99(77.3)$ \\
\hline Serous papillary & $4(3)$ \\
\hline Adenoacanthoma & $5(4)$ \\
\hline Adenosquamous & $19(14.8)$ \\
\hline Clear cell & $1(0.9)$ \\
\hline \multicolumn{2}{|l|}{ Lymph node status } \\
\hline Negative & $111(86.7)$ \\
\hline Positive & $17(13.3)$ \\
\hline \multicolumn{2}{|l|}{ Expression of MMP9 } \\
\hline Low expression & $74(57.8)$ \\
\hline High expression & $54(42.2)$ \\
\hline
\end{tabular}

with endometrial cancer are summarized in Table 2 . We did not find a significant association of MMP9 expression levels with patient's age, menopausal status, FIGO stage, and depth of myometrial invasion in $128 \mathrm{EC}$ cases. However, we observed that the expression level of MMP9 was positively correlated with the status of lymph node metastasis (Negative vs. Positive) $(P=$ $0.044)$, and histopathological grade (G1 vs. G2 vs. G3) $(P<0.05)$ in EC patients (Table 3$)$.

\subsection{Survival analysis}

To investigate the prognostic value of MMP9 expression for endometrial cancer, we assessed the association between the levels of MMP9 expression and patients' survival using Kaplan-Meier analysis with the log-rank test. In $128 \mathrm{EC}$ cases with prognosis information, we observed that the level of MMP9 protein expression was not correlated with the overall survival of EC patients (Fig. 1B). In addition, we performed multivariate analysis of the levels of MMP9 protein expression adjusted for age, family history of tumor, education, Health Insurance(there are Medicare patients whose $80 \%$ of their medical expenses would be paid by the Government), career, menopausal status, FIGO stage, histological grading, depth of myometrial invasion, lymph node status, complications (including high blood pressure or diabetes mellitus or heart disease), histologic subtype, postoperative irradiation, chemotherapy, and hormone therapy of EC patients. The results showed that status of lymph node metastasis and depth of myometrial invasion, but not MMP-9, were significantly correlated with patients' survival $(P=0.040, P=$ 0.030 , respectively) (Table 4).

\section{Discussion}

Ninety-seven percent of all cancers of the uterus arise from the glands of the endometrium and are known as endometrial carcinomas [13]. A multi-step endometrial carcinogenesis involving coordinated intervention of hormonal regulation, gene mutation, adhesion molecules, apoptosis, imbalance between metalloproteinases (MMPs), and tissue inhibitors of MMPs (TIMPs) is currently accepted [14]. It is the most curable of the 10 most common cancers in women and the most frequent and curable of the gynecologic cancers when found early. The majority of the EC deaths attribute to tumor metastases rather than primary tumors. However, the molecular mechanism of EC invasion and metastasis remains incompletely understood.

In some of the previous studies, increased amount or activity of MMP9 had been found by different methods (sandwich immunoassay, zymography, ELISA, and in situ hybridization for mRNA) in cancer-affected endometrium compared to a benign one [5,10,14,15]. This is in accordance with their study, we found that the levels of MMP9 were higher in EC tissues than those in non-cancerous endometrial tissues including EAHs and NEs by immunohistochemistry assay, suggesting that MMP9 was involved in the pathogenesis of EC.

MMP9 is a $\mathrm{Zn} 2+$ dependent endopeptidase that mediates the degradation of extracellular matrix protein [3], and is associated with tumor invasion and metastasis $[16,17]$. It is synthesized and secreted in 
Table 3

Correlation between the clinicopathologic characteristics and expression of MMP9 protein in EC

\begin{tabular}{|c|c|c|c|c|}
\hline \multirow[b]{2}{*}{ Characteristics } & \multirow[b]{2}{*}{$\mathrm{N}$} & \multicolumn{2}{|c|}{ MMP-9 (\%) } & \multirow[b]{2}{*}{$\mathrm{P}$} \\
\hline & & High expression & Low expression & \\
\hline \multicolumn{5}{|l|}{ Age } \\
\hline$<50$ & 42 & $2(52.4 \%)$ & $20(47.6 \%)$ & 0.386 \\
\hline$\geqq 50$ & 86 & $52(60.5 \%)$ & $34(39.5 \%)$ & \\
\hline \multicolumn{5}{|l|}{ Menopausal status } \\
\hline Premenopausal & 69 & $37(53.6 \%)$ & $32(46.4 \%)$ & 0.301 \\
\hline Postmenopausal & 59 & $37(62.7 \%)$ & $22(37.3 \%)$ & \\
\hline \multicolumn{5}{|l|}{ FIGO stage } \\
\hline I-II & 108 & $65(60.2 \%)$ & $43(39.8 \%)$ & \\
\hline III & 20 & $9(45 \%)$ & $11(55 \%)$ & 0.208 \\
\hline \multicolumn{5}{|l|}{ Histological grading } \\
\hline G1 & 56 & $38(67.9 \%)$ & $18(32.1 \%)$ & 0.044 \\
\hline $\mathrm{G} 2$ & 57 & $31(54.4 \%)$ & $26(45.6 \%)$ & \\
\hline G3 & 15 & $5(33.3 \%)$ & $10(66.7 \%)$ & \\
\hline \multicolumn{5}{|c|}{ Depth of myometrial invasion } \\
\hline$<50 \%$ & 91 & $56(61.5 \%)$ & $35(38.5 \%)$ & 0.182 \\
\hline$\geqq 50 \%$ & 37 & $18(48.6 \%)$ & $19(51.4 \%)$ & \\
\hline \multicolumn{5}{|l|}{ Lymph node status } \\
\hline Negative & 111 & $68(61.3 \%)$ & $43(38.7 \%)$ & \\
\hline Positive & 17 & $6(35.3 \%)$ & $11(64.7 \%)$ & 0.044 \\
\hline
\end{tabular}

Table 4

Summary of univariate and multivariate Cox regression analysis of overall survival duration

\begin{tabular}{|c|c|c|c|c|c|c|}
\hline \multirow[b]{2}{*}{ Parameter } & \multicolumn{3}{|c|}{ Univariate analysis } & \multicolumn{3}{|c|}{ Multivariate analysis } \\
\hline & $\mathrm{P}$ & HR & $95 \% \mathrm{CI}$ & $\mathrm{P}$ & HR & $95 \% \mathrm{CI}$ \\
\hline Age & & & & & & \\
\hline$<50$ vs. $\geqq 50$ & 0.652 & & & 0.354 & & \\
\hline Family history of tumor & & & & & & \\
\hline $\begin{array}{l}\text { Negative vs. Positive } \\
\text { Education }\end{array}$ & 0.353 & & & 0.486 & & \\
\hline $\begin{array}{l}<\text { graduation vs. } \geqq \text { graduation } \\
\text { Health Insurance }\end{array}$ & 0.801 & & & 0.710 & & \\
\hline $\begin{array}{l}\text { No vs. yes } \\
\text { Career }\end{array}$ & 0.230 & & & 0.359 & & \\
\hline $\begin{array}{l}\text { Career } \\
\text { Worker vs. Worker } \\
\text { Menopausal status }\end{array}$ & 0.274 & & & 0.861 & & \\
\hline $\begin{array}{l}\text { Premenopausal vs. Postmenopausal } \\
\text { complications }\end{array}$ & 0.971 & & & 0.398 & & \\
\hline $\begin{array}{l}\text { with vs. without } \\
\text { FIGO stage }\end{array}$ & 0.350 & & & 0.156 & & \\
\hline $\begin{array}{l}\text { I vs. II vs. III } \\
\text { Histological grading }\end{array}$ & $\leqslant 0.001$ & 2.816 & $1.595-4.973$ & 0.404 & & \\
\hline $\begin{array}{l}\text { G1 vs. G2 vs. G3 } \\
\text { Histologic subtype }\end{array}$ & 0.021 & 2.517 & $1.147-5.523$ & 0.231 & & \\
\hline $\begin{array}{l}\text { Endometrioid adenocarcinoma vs. others } \\
\text { Lymph node status }\end{array}$ & 0.141 & & & 0.975 & & \\
\hline $\begin{array}{l}\text { Negative vs. Positive } \\
\text { Depth of myometrial invasion }\end{array}$ & $\leqslant 0.001$ & 9.760 & $3.376-28.214$ & 0.040 & 79.073 & $1.211-5.165$ \\
\hline $\begin{array}{l}<50 \% \text { vs. } \geqq 50 \% \\
\text { MMP expression }\end{array}$ & $\leqslant 0.001$ & 6.076 & $2.010-18.370$ & 0.030 & 4.569 & $1.155-18.006$ \\
\hline $\begin{array}{l}\text { Low expression vs. High expression } \\
\text { Postoperative irradiation }\end{array}$ & 0.271 & & & 0.773 & & \\
\hline with vs. without & 0.153 & & & 0.249 & & \\
\hline $\begin{array}{l}\text { Postoperative chemotherapy } \\
\text { with vs. without }\end{array}$ & 0.013 & 4.162 & $1.356-12.776$ & 0.272 & & \\
\hline $\begin{array}{l}\text { Postoperative hormone therapy } \\
\text { with vs. without }\end{array}$ & 0.278 & & & 0.892 & & \\
\hline
\end{tabular}


monomeric form as zymogen, and belongs to the gelatinase subgroup. Increased expression of MMP9 is usually seen in invasive and metastatic cancers such as colorectal cancer [18], gastric carcinoma [19], pancreatic carcinoma [20], breast cancer [21], and oral cancer [22]. The levels of MMP9 expression have also been found to be increased in nasal NK/T-cell lymphoma [23], malignant astrocytomas, carcinomatousmeningitis, and brain metastases [24]. In this study, we also found that MMP9 overexpression was significantly associated with lymph node metastasis and histopathological grade of EC patients. Overexpressed MMP9 in EC may accelerate tumor growth by inducing angiogenesis and enhance local cell invasion and metastasis by degrading the extracellular matrix. Our results may indicate that MMP9 plays significant roles in endometrial cancer progression, including tumor invasion and metastasis. These results were analogous to Di Nezza et al. and Aglund et al.'s reports [7] but inconsistent with Honkavuori et al.'s investigation. Di Nezza et al. used immunohistochemistry assay in EC tissues to find MMP9 staining scores in tumor cells were significantly associated with the presence of myometrial invasion and vascular/lymphatic invasion. Furthermore, Aglund et al. showed that increased expression of MMP9 protein was associated with histologic grade and clinical stage. However, in the study of Honkavuori et al., they did not find any correlations between MMP9 immunostaining and conventional prognostic indicators of endometrial cancer. The discrepancy between our data and Honkavuori et al.'s data would be most likely due to the different samples sources.

Survival analyses for MMP9 expression have been done in endometrial carcinoma in previous studies [5, $6,8,25]$, however, the role of MMP9 in tumor development and progression remains to be unclear. In the present study, we presented the evidence that MMP9 protein expression in endometrial carcinoma was not correlated with patient's overall survival. These results were in accordance with previous report $[6,8,25]$. Aglund et al. used immunohistochemistry assay in endometrial carcinoma tissues to observe that a positive MMP9 staining seemed to predict a poorer outcome of the disease compared to a negative staining, but it was not statistically significant $(P=0.25)$. One explanation for the phenomenon could be that death was relatively infrequent in the present study due to the fact that endometrial carcinoma is generally a relatively low-risk malignancy.

Finally, we also performed univariate and multivariate analyses for the detailed factors including clin- icopathological characteristics, family history of tumor, education, Health Insurance, career, complications, histologic subtype and postoperative therapy so far that might exert effects on prognosis of endometrial carcinoma patients. Our results demonstrated that increased expression of MMP9 protein was not a significant predictor of poor prognosis for EC patients, but depth of myometrial invasion and lymph node status were a statistically significant predictor of survival in a 5-year period. We observed that patients with greater than or equal to $50 \%$ with the depth of myometrial invasion or lymph node metastasis had a poorer outcome than that of control group, which suggested that depth of myometrial invasion and lymph node status might guide therapeutic decisions in endometrial carcinoma.

\section{Conclusion}

In summary, our study demonstrated that the expression level of MMP9 was significantly increased in endometrial carcinoma and correlated with the malignant status of EC. Furthermore, our data suggested that MMP9 did not correlate with EC patients' clinical outcome in China. Yet, due to the limited sample size of patients in our investigation, further studies would be needed to verify these findings, such as increasing sample size of patients to verify our results and importing MMP9 gene into endometrial cancer cell lines and observing the effects of MMP9 on cell proliferation, migration, invasion, and metastasis in vitro as well as the rate of tumorigenesis and survival time of nude mice with transplanted tumor in vivo. Finally, our investigation also indicated the possibility for depth of myometrial invasion and lymph node status guiding therapeutic decisions in endometrial carcinoma.

\section{Acknowledgements}

Grants support: The natural science foundation of Guangdong Province (No. 8151051501000058).

\section{References}

[1] F. Amant, P. Moerman, P. Neven, D. Timmerman, E. Van Limbergen, and I. Vergote, Endometrial cancer. Lancet 366 (2005), 491-505.

[2] A. Jemal, R.C. Tiwari, T. Murray, A. Ghafoor, A. Samuels, E. Ward, E.J. Feuer and M.J. Thun, Cancer statistics, 2004. CA Cancer J Clin 54 (2004), 8-29. 
[3] R. Fridman, M. Toth, D. Pena and S. Mobashery, Activation of progelatinase B (MMP-9) by gelatinase A (MMP-2). Cancer Res 55 (1995), 2548-2555.

[4] J.R. Backstrom and Z.A. Tokes, The 84-kDa form of human matrix metalloproteinase- 9 degrades substance $P$ and gelatin. J Neurochem 64 (1995), 1312-1318.

[5] M. Iurlaro, G. Loverro, A. Vacca, G. Cormio, D. Ribatti, M. Minischetti, R. Ria, M. Bruno and L. Selvaggi, Angiogenesis extent and expression of matrix metalloproteinase-2 and -9 correlate with upgrading and myometrial invasion in endometrial carcinoma. Eur J Clin Invest 29 (1999) 793-801.

[6] K. Aglund, M. Rauvala, U. Puistola, T.Angstrom, T. Turpeenniemi-Hujanen, B. Zackrisson and U. Stendahl, Gelatinases A and B (MMP-2 and MMP-9) in endometrial cancer-MMP-9 correlates to the grade and the stage. Gynecologic Oncology 94 (2004), 699-704.

[7] L.A. Di Nezza, A. Misajon, J. Zhang, T. Jobling, M.A. Quinn, A.G. Ostor, G. Nie, A. Lopata and L.A. Salamonsen, Presence of active gelatinases in endometrial carcinoma and correlation of matrix metalloproteinase expression with increasing tumor grade and invasion. Cancer 94 (2002), 1466-1475.

[8] M. Honkavuori, A. Talvensaari-Mattila, Y. Soini, T. Turpeenniemi-Hujanen and M. Santala, MMP-2 expression associates with CA 125 and clinical course in endometrial carcinoma. Gynecol Oncol 104 (2007), 217-221.

[9] W. Guo, G. Chen, C. Zhu and H. Wang, [Expression of matrix metalloproteinase-2, 9 and it's tissue inhibitor-1, 2 in endometrial carcinoma]. Zhonghua Fu Chan Ke Za Zhi 37 (2002), 604-607.

[10] C. Amalinei, C. Cianga, R. Balan, P. Cianga, S. Giusca and I.D. Caruntu, Immunohistochemical analysis of steroid receptors, proliferation markers, apoptosis related molecules, and gelatinases in non-neoplastic and neoplastic endometrium. Ann Anat 193 (2011), 43-55.

[11] R. Masunaga, H. Kohno, D.K. Dhar, S. Ohno, M. Shibakita, S. Kinugasa, H. Yoshimura, M. Tachibana, H. Kubota and N. Nagasue, Cyclooxygenase-2 expression correlates with tumor neovascularization and prognosis in human colorectal carcinoma patients. Clin Cancer Res 6 (2000), 4064-4068.

[12] Z. Liu, L. Li, Z. Yang, W. Luo, X. Li, H. Yang, K. Yao, B. Wu, and W. Fang, Increased expression of MMP9 is correlated with poor prognosis of nasopharyngeal carcinoma. BMC Cancer 10 (2010), 270.

[13] P.G. Rose, Endometrial carcinoma. N Engl J Med 335 (1996), 640-649.

[14] O. Graesslin, A. Cortez, R. Fauvet, M. Lorenzato, P. Birembaut and E. Darai, Metalloproteinase-2, -7 and -9 and tissue inhibitor of metalloproteinase- 1 and -2 expression in normal, hyperplastic and neoplastic endometrium: a clinicalpathological correlation study. Ann Oncol 17 (2006), 637645
[15] S.M. Laird, C.F. Dalton, M.A. Okon, R.A. Bunning, R. Marshall, and T.C. Li, Metalloproteinases and tissue inhibitor of metalloproteinase 1 (TIMP-1) in endometrial flushings from pre- and post-menopausal women and from women with endometrial adenocarcinoma. J Reprod Fertil 115 (1999), 225232.

[16] L.F. Lin, C.H. Chuang, C.F. Li, C.C. Liao, C.P. Cheng, T.L. Cheng, M.R. Shen, J.T. Tseng, W.C. Chang, W.H. Lee and J.M. Wang, ZBRK1 acts as a metastatic suppressor by directly regulating MMP9 in cervical cancer. Cancer Res 70 (2010), 192-201.

[17] M. Loesch, H.Y. Zhi, S.W. Hou, X.M. Qi, R.S. Li, Z. Basir, T. Iftner, A. Cuenda and G. Chen, p38gamma MAPK cooperates with c-Jun in trans-activating matrix metalloproteinase 9. J Biol Chem 285 (2010), 15149-15158.

[18] R. Bendardaf, A. Buhmeida, M. Hilska, M. Laato, S. Syrjanen, K. Syrjanen, Y. Collan and S. Pyrhonen, MMP-9 (gelatinase B) expression is associated with disease-free survival and diseasespecific survival in colorectal cancer patients. Cancer Invest 28 (2010), 38-43.

[19] Z.S. Zhao, Y.Y. Wang, Z.Y. Ye and H.Q. Tao, Prognostic value of tumor-related molecular expression in gastric carcinoma. Pathol Oncol Res 15 (2009), 589-596.

[20] M. Tian, Y.Z. Cui, G.H. Song, M.J. Zong, X.Y. Zhou, Y. Chen, and J.X. Han, Proteomic analysis identifies MMP-9, DJ-1 and A1BG as overexpressed proteins in pancreatic juice from pancreatic ductal adenocarcinoma patients. BMC Cancer 8 (2008), 241.

[21] X. Provatopoulou, A. Gounaris, E. Kalogera, F. Zagouri, I. Flessas, E. Goussetis, A. Nonni, I. Papassotiriou and G. Zografos, Circulating levels of matrix metalloproteinase-9 (MMP-9), neutrophil gelatinase-associated lipocalin (NGAL) and their complex MMP-9/NGAL in breast cancer disease. BMC Cancer 9 (2009), 390.

[22] B.P. Patel, S.V. Shah, S.N. Shukla, P.M. Shah and P.S. Patel, Clinical significance of MMP-2 and MMP-9 in patients with oral cancer. Head Neck 29 (2007), 564-572.

[23] K. Sakata, M. Someya, M. Omatsu, H. Asanuma, T. Hasegawa, S. Ichimiya, M. Hareyama and T. Himi, The enhanced expression of the matrix metalloproteinase 9 in nasal NK/T-cell lymphoma. BMC Cancer 7 (2007), 229.

[24] M.H. Friedberg, M.J. Glantz, M.S. Klempner, B.F. Cole and G. Perides, Specific matrix metalloproteinase profiles in the cerebrospinal fluid correlated with the presence of malignant astrocytomas, brain metastases, and carcinomatous meningitis. Cancer 82 (1998), 923-930.

[25] Y. Inoue, K. Abe, K. Obata, T. Yoshioka, G. Ohmura, K. Doh, K. Yamamoto, H. Hoshiai and K. Noda, Immunohistochemical studies on matrix metalloproteinase-9 (MMP-9) and type-IV collagen in endometrial carcinoma. J Obstet Gynaecol Res 23 (1997), 139-145. 


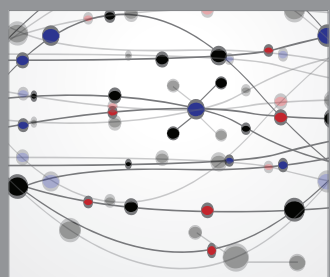

The Scientific World Journal
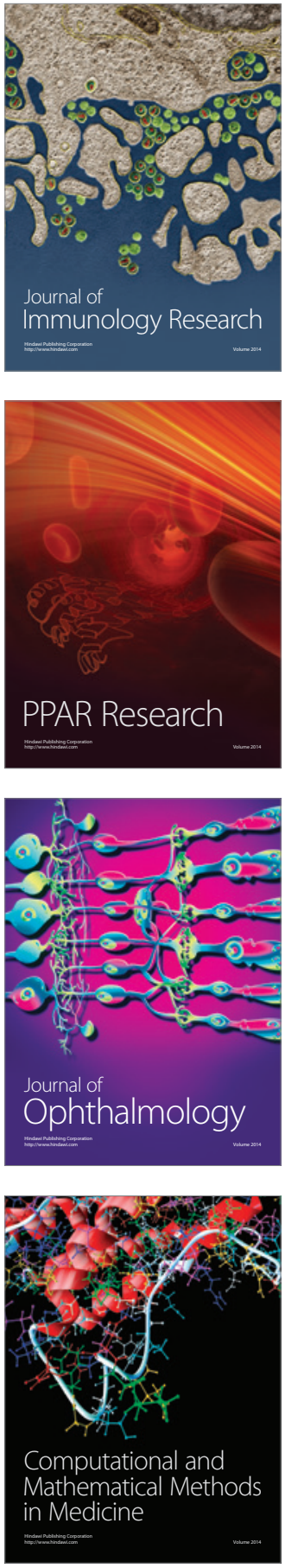

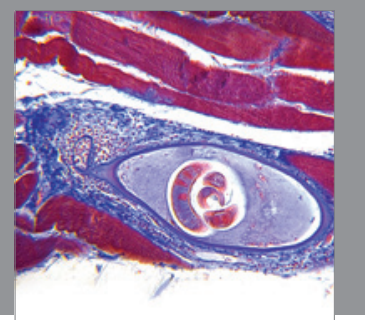

Gastroenterology

Research and Practice
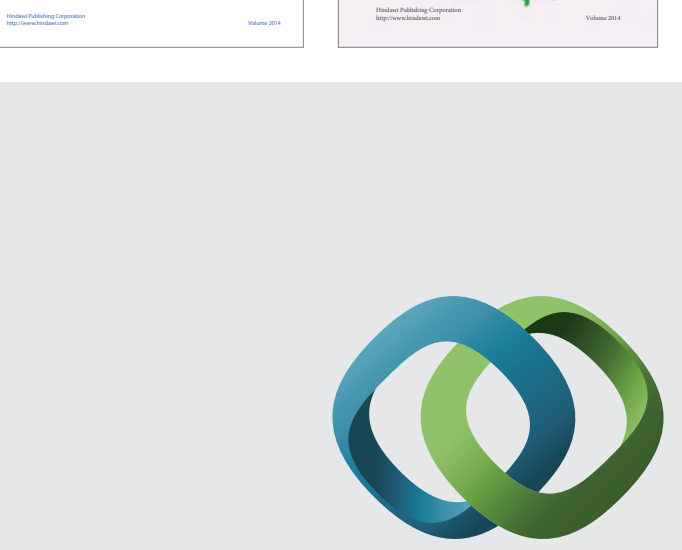

\section{Hindawi}

Submit your manuscripts at

http://www.hindawi.com
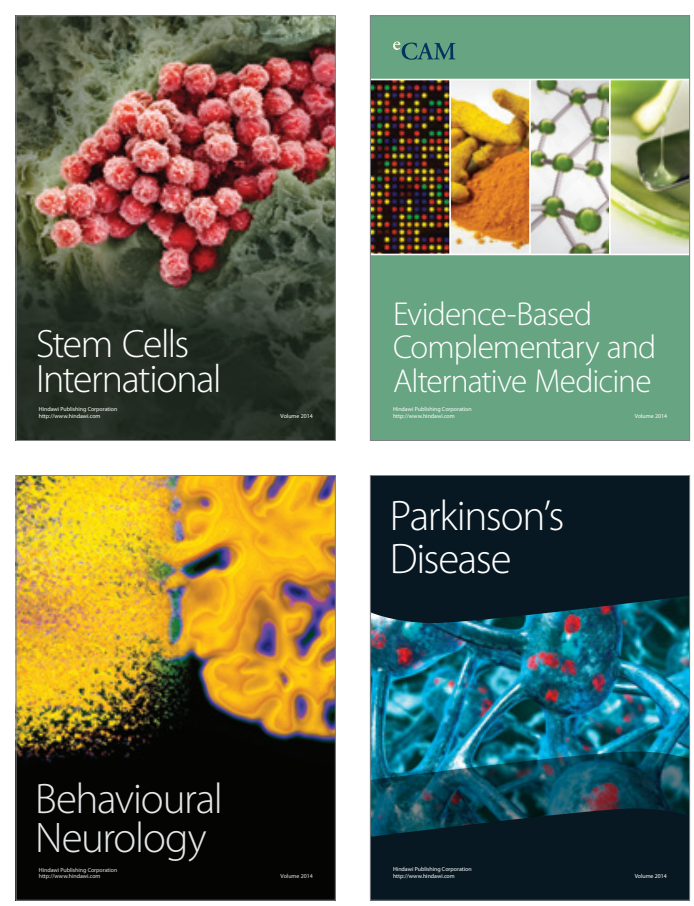

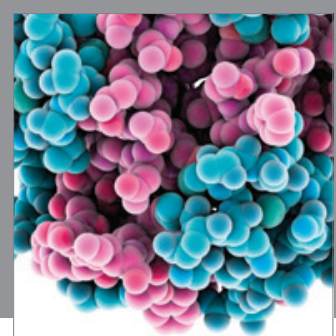

Journal of
Diabetes Research

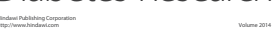

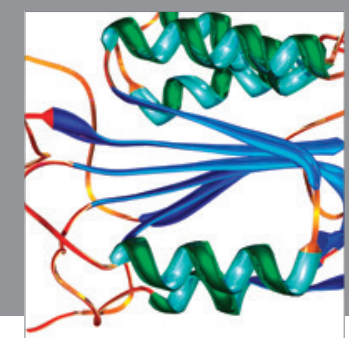

Disease Markers
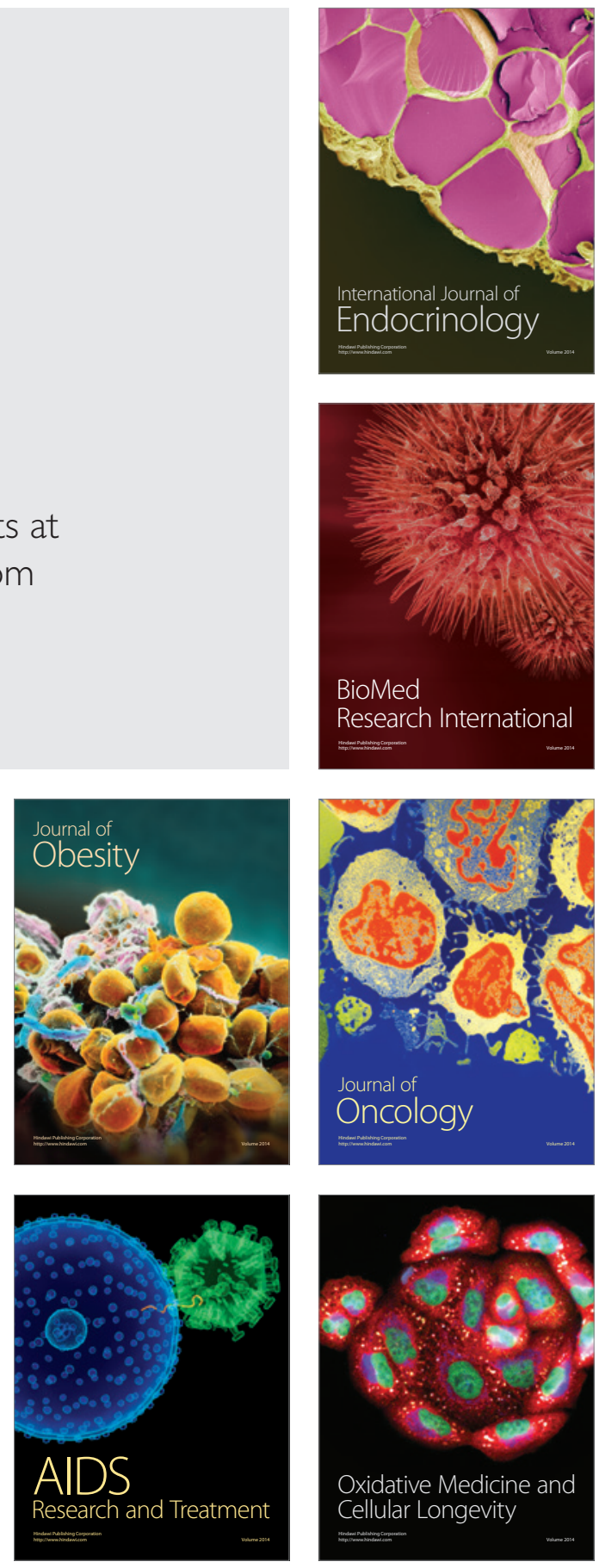